\title{
Comparative simulation of the nitrogen dynamics using the INCA model and a neural network analysis: implications for improved nitrogen modelling
}

\author{
G. Lischeid and J. Langusch \\ BITÖK, University of Bayreuth, Dr. Hans-Frisch-Str. 1-3, 95440 Bayreuth, Germany
}

Email for corresponding author: Gunnar.Lischeid@bitoek.uni-bayreuth.de

\begin{abstract}
Continuing deposition of nitrogen in forested catchments affects stream and groundwater quality. However, the dependence of nitrogen dynamics on climatic and hydrological boundary conditions is still poorly understood. These dynamics have been investigated by applying the process-oriented Integrated Nitrogen in CAtchments (INCA) model and an artificial neural network to the data set from the forested Steinkreuz catchment in South Germany. The data comprise daily values of precipitation, air temperature and discharge of the catchment runoff. The INCA model simulated the mean nitrate concentration in the stream as well as seasonal fluctuations but it underestimated the short-term variance of the observed stream water nitrate concentration, especially the pronounced concentration peaks in late summer. In contrast, the artificial neural network matched the short-term dynamics using non-linear regressions with stream discharge and air temperature data. The results provide strong evidence that the short-term dynamics of stream nitrate concentration during storm-flow were generated in the riparian zone, which is less than $1 \%$ of the catchment area, and is not considered explicitly in the INCA model. The concentration peaks have little effect on the catchment's nitrogen budget and the shallow groundwater data suggest that the short-term hydrological dynamics also govern groundwater recharge in the upland parts of the catchment. This substantial underestimate by the INCA model parameterisation is balanced by a corresponding underestimate of denitrification in clayey layers of the deeper aquifer. A better understanding of these processes is necessary to improve long-term risk assessments.
\end{abstract}

Keywords: catchment, runoff, nitrogen, INCA, artificial neural network, flushing

\section{Introduction}

Long-lasting deposition of nitrogen compounds in Middle Europe may have severe implications on stream and ground water quality especially in forested areas where, for decades, deposition rates have exceeded the annual plant uptake rates. (Stoddard et al., 2001; Lovett et al., 2000; Dise and Wright, 1995; Aber et al., 1989). To assess the long-term risk to stream and ground water quality, as well as the impact of climate change on decomposition and nitrogen release from the soil organic pool, a thorough understanding of the nitrogen dynamics is necessary. Despite a plethora of studies, there are substantial uncertainties in respect of the nitrogen dynamics depending, e.g. on short-term climatic and hydrological variations (Mitchell, 2001; Stoddard et al., 1999; Wright and Hauhs, 1991). Hence, intensive monitoring programmes at selected sites have been combined with modelling approaches:

- to investigate the turnover of air-borne nitrogen in forested catchments.

- to assess the long-term nitrogen dynamics.

- to focus on non-linear effects with special regard to climate change.

This focus of the analysis is to understand the key processes and issues involved and to improve models of the short-term dynamics. These two aspects are interrelated and the modelling work, coupled with recourse to the field measurements, can reveal important information about the predominating processes. 
Many model tests focus on quantifying the residuals, namely, the differences between simulated and corresponding observations. However, comparing the structure of the observed and the simulated data can help to improve understanding of the processes and enhance future model development. To that end, a process-based model and an empirical, non-linear model were applied to the same data set. Such an approach has been successful in analysing the predominant processes of runoff and silica dynamics in a mountainous catchment and improving a process-based model of these dynamics (Lischeid and Uhlenbrook, 2003). In this study, comparing the results of the two models focused on the following questions:

- which features of the data set do the single models map well?

- can the differences between the two models be explained by the different model structures?

- can similar results of the two model approaches be explained despite the different model structures?

- what hints does the model comparison give on how the process-based model can be improved? namely, which additional processes should be included and which processes can be neglected?

The semi-distributed process-oriented INCA model (Integrated Nitrogen in CAtchments; Whitehead et al., 1998a; Wade, 2004) was applied to simulate daily nitrogen concentrations in the runoff of the small forested Steinkreuz catchment in South Germany (Langusch and Matzner, 2002). The results were compared with those of an artificial neural network, which was used to assess how much of the observed variance was explained by the input data, independent of a specific model structure. This was done to identify the driving variables of the observed dynamics, to determine time lags between driving variables and nitrate dynamics, and to visualise the internal structure of the data sets to improve understanding of the dynamics and to check for consistency with existing models.

\section{STUDY SITE}

The Steinkreuz catchment, located at the western edge of the Steigerwald lower mountainous region in south Germany, at $10^{\circ} 28^{\prime} \mathrm{E}$ and $49^{\circ} 52^{\prime} \mathrm{N}$, is $0.55 \mathrm{~km}^{2}$ in area at an altitude of between $405-460 \mathrm{~m}$ a.s.l. The bedrock comprises sediments of the middle Keuper (Late Triassic), dipping $2.5 \%$ toward the south-east, as has been confirmed by geo-radar and geo-electrical surveys in the catchment (Lischeid et al., 2004). The sediments comprise a heterogeneous interbedding of sandstone and silty clay layers. The weir is sited in the upper layers of the Lehrbergschichten which consist of 25-30 m thick red silty clay layers and serve as an aquiclude. No major fault fractured zones are known in the vicinity of the catchment. However, $\mathrm{Cl}$ mass balance calculations suggest that approximately $33 \%$ of the catchment water output flux bypasses the weir (Lischeid et al., 2004). Compared to the 1995 to 1998 discharge of the two large rivers that drain the Steigerwald, the Rauhe Ebrach and the Reiche Ebrach, the Steinkreuz discharge is underestimated by approximately $20 \%$.

Soils are classified mostly as loamy sandy cambisols with low to medium base saturation. The soils exhibit gleyic properties where thin clayey layers outcrop, mainly in the upper part of the catchment but there are no wetlands in the catchment. Also, sandy soils predominate in the riparian zone, which is less than $2 \mathrm{~m}$ wide along the stream.

Mean air temperature from 1995 to 2000 was $7.9^{\circ} \mathrm{C}$, in the upper range for long term mean values in that region, and annual precipitation averaged $780 \mathrm{~mm}$. The vegetation is deciduous, mainly European beech (Fagus sylvatica) and sessile oak (Quercus petraea) up to about 155 years old. The site was part of the extensive forest of the Monastery of Ebrach, founded in 1127, $4 \mathrm{~km}$ south east of the present investigation. Excluding a small area of about 1.5 ha in the early 19th century, for centuries, the exclusive land use was forestry. In addition, farmers were forbidden to graze cattle in the forest or to use litter as fodder. As such, these conditions may have favoured the build-up of a large nitrogen pool in the topsoil; this pool comprises $3000 \mathrm{~kg} \mathrm{~N}$ $\mathrm{ha}^{-1}$ in the upper $15 \mathrm{~cm}$ layer (Chang, 1999) and a another $3000 \mathrm{~kg} \mathrm{~N} \mathrm{ha}^{-1}$ in the underlying $1 \mathrm{~m}$ layer (Langusch and Kalbitz, 2001).

The annual mean nitrogen input measured in open field

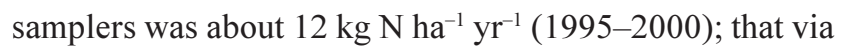
throughfall and stemflow was about $20 \mathrm{~kg} \mathrm{~N} \mathrm{ha}^{-1} \mathrm{yr}^{-1}$. Annual mean nitrogen output via the catchment runoff is $2.3 \mathrm{~kg} \mathrm{~N} \mathrm{ha}^{-1} \mathrm{yr}^{-1}$, mostly as nitrate. Given that the measurements at the weir underestimate the total output flux by $33 \%$, the annual mean nitrogen output is only $15 \%$ of the nitrogen deposition via throughfall and stemflow.

\section{MEASUREMENTS}

Biogeochemical monitoring in the Steinkreuz catchment started in the end of 1994. Open field deposition and meteorological measurements, including precipitation, air temperature, humidity, radiation, wind-speed and winddirection are measured at an open field site close to the western watershed of the catchment (Fig. 1). Throughfall deposition is measured using 12 samplers and stemflow at 


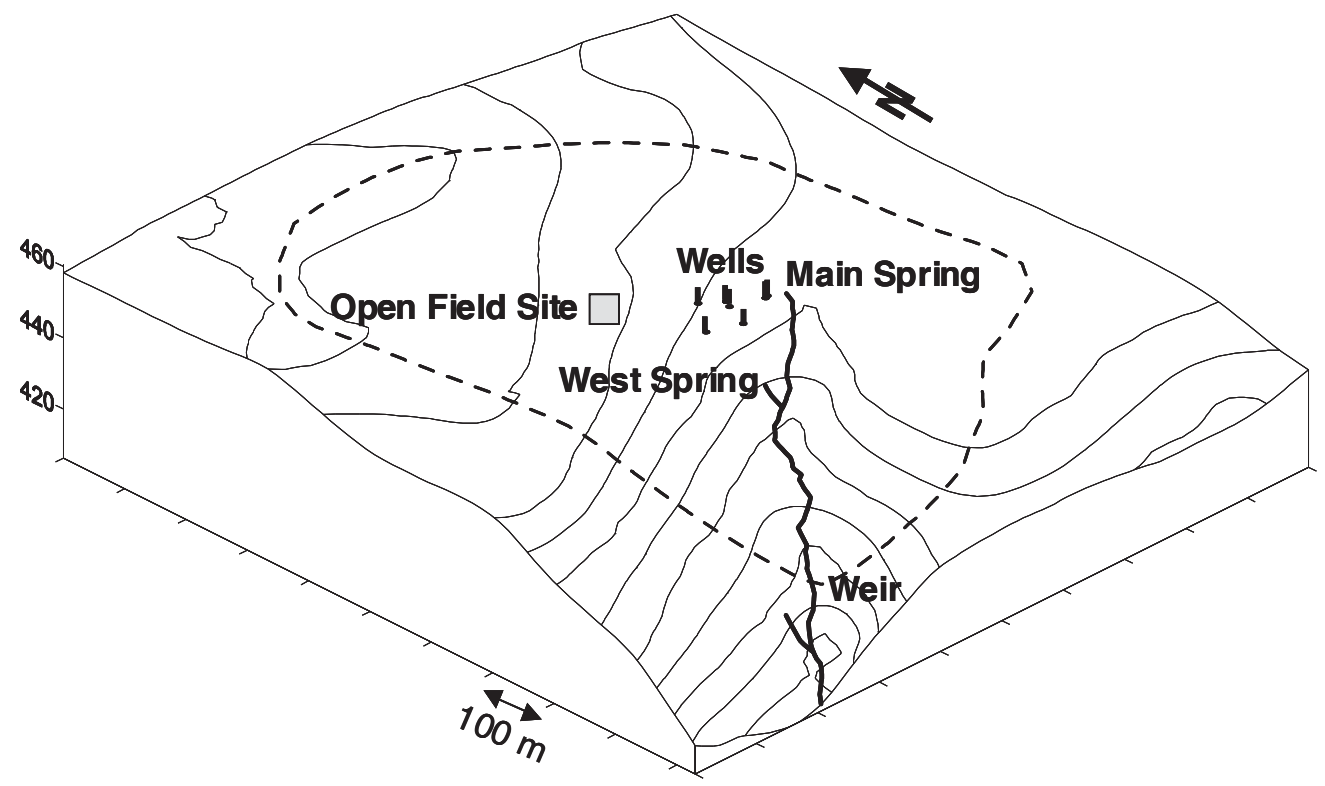

Fig. 1. Map of the Steinkreuz catchment. Contour lines at $10 \mathrm{~m}$ interval, the altitude is given at the left axis ( $m$ a.m.s.l.)

five beech trunks in the stand. Soil solution concentration has been sampled by up to 111 soil suction cups with constant vacuum of about $-200 \mathrm{hPa}$ at depths of $10,20,35$, 60 and $90 \mathrm{~cm}$ at different distances from the trees from June 1995 to December 1996. Thereafter, the monitoring programme was reduced to 18 representative cups that have been sampled continuously since then. Close to the suction cups, six shallow wells, $2.85 \mathrm{~m}$ in depth and another well $5.5 \mathrm{~m}$ in depth above hydraulically tight layers, sampled soil water from transiently saturated layers since 1997 . The clayey basis of this perched aquifer dips towards the stream and outcrops near the springs. A deep well, gauged between 20.5 to $24.5 \mathrm{~m}$, was installed in 2000; this well sampled the deepest aquifer that contributed to the catchment runoff. Here, the groundwater table was always at least $15 \mathrm{~m}$ below the springs. Since installation, this well has not run dry.

Precipitation, soil suction, stream stage and groundwater levels have been measured biweekly since 1995. On occasion, additional stream water samples were taken by automatic samplers. Discharge is measured continuously by pressure transducers as well as by an ultrasonic device at a V-notch weir at the catchment outlet. Soil matrix potential was measured at depths of 20 to $200 \mathrm{~m}$ with up to 47 replicates while soil moisture was recorded hourly by 9 TDR probes at depths of 20,35 and $90 \mathrm{~cm}$.

Water samples were stored in the dark at $2{ }^{\circ} \mathrm{C}$, filtered $(0.45 \mu \mathrm{m})$ and analysed in the BITÖK central laboratory, usually within 24 hours. Major anions, including $\mathrm{NO}_{3}$ and $\mathrm{NO}_{2}$, were determined by ion chromatography and major cations by atomic emission spectroscopy using inductively coupled plasma analysis. Ammonium was determined by photometric detection with a flow injection system, and total dissolved nitrogen as $\mathrm{NO}_{\mathrm{x}}$ after thermo-oxidation. Dissolved organic nitrogen was calculated as the difference between total nitrogen and inorganic nitrogen. However, $\mathrm{NH}_{4}, \mathrm{NO}_{2}$ and organic nitrogen were detected only in negligible quantities in the groundwater and in the stream water (Lischeid et al., 2004). Thus, only nitrate concentration values are given in this paper.

\section{Models}

\section{THE PROCESS-BASED APPROACH: INCA}

The Integrated Nitrogen in Catchments (INCA) model aims to simulate the nitrogen dynamics in soils, groundwaters and streams of large catchments, considering different sources of nitrogen (deposition, manure, fertilisers, sewage plants) and different land use subunits (Whitehead et al.,1998a,b; Wade et al., 2002). The model considers processes in the plant/soil system, namely plant uptake, ammonia nitrification, denitrification, mineralisation, immobilisation and nitrogen fixation, and the within-stream processes of nitrification and denitrification. The model simulates a daily resolution. The groundwater zone is assumed to be biochemically inert.

The INCA model, version 1.6.1, has been applied to the Steinkreuz data set from January 1995 to December 1999. Only one land-use type (deciduous forest) was selected. The soil nitrogen pools were assumed to be at steady state. 
Mineralisation and immobilisation of $\mathrm{NH}_{4}$, and fixation of $\mathrm{NO}_{3}$, were set to zero, as the available data did not give any evidence for these processes. Denitrification was set to a rather low value of $0.002 \mathrm{~m} \mathrm{day}^{-1}$, as there are no wetlands and only occasionally hydromorphic soils in the catchments. The resulting annual denitrification sink was about $5.27 \mathrm{~kg}$ $\mathrm{ha}^{-1} \mathrm{yr}^{-1}$.

The soil water deficit and the effective rainfall were calculated with the Hydrus 2D model (Simúnek et al., 1996), where the effective rainfall required by the INCA model was set equal to the seepage flux calculated at $60 \mathrm{~cm}$ depth. To account for groundwater loss underneath the weir, the measured catchment runoff was multiplied by 1.3 . The time constant of residence of water in the soil reactive zone was set as 1 day, and that for groundwater as 40 days, based on annual mean groundwater recharge data and the total groundwater volume. However, this is a rough estimate, as only one groundwater well reaches the deepest groundwater layer. The base flow index was set to 0.55 . The hydrological parameters were adjusted to fit the observed hydrograph. Further details of the parameterisation of the model are given in Langusch and Matzner (2002).

\section{THE DATA-ORIENTED APPROACH: ARTIFICIAL}

\section{NEURAL NETWORKS}

Artificial neural networks have been used to simulate hydrochemical time series in numerous studies (Maier and Dandy, 1996; Walter et al., 2001; Huang and Foo, 2002). Unlike the process-based modelling approach, they are based not on the implementation of knowledge about processes but on the detection of structures in large, multivariate data sets. Contrary to most neural network studies, however, the focus of this study is not prediction but analysis of the data set.

In simplified terms, the type of network used in this study performs a non-linear regression between input variables and an output variable, i.e. $\mathrm{NO}_{3}$ concentration in the catchment runoff. This analysis allows an assessment of how much of the observed variance of the $\mathrm{NO}_{3}$ time series can be explained by the input data, independent of a specific model structure, and can be compared to that of the processbased model. Moreover, the most important driving variables can be identified from a variety of candidate variables. In addition, the time lags between driving variables and nitrate dynamics can be determined. Furthermore, the relationship between the driving variables and the output variables, as identified by the network, can be visualised. These results can be checked for consistency with the process-based model and thus can be used to improve the latter. Although this focus on neural network analysis is rarely considered in hydrology, its potential has been proven in previous studies (Lischeid, 2001a; Lischeid and Uhlenbrook, 2003).

The type of network used in this study was the multilayer perceptron. Here, three layers were selected. The input layer consisted of one node for every driving variable. These variables were identified from a number of candidates by the skeletonisation method (Mozer und Smolensky, 1989) as a 'pruning procedure'. This identifies the driving variables by stepwise deletion of input nodes that do not contribute to the performance of the model. Five nodes in the hidden layer proved sufficient to map the non-linear relationship between input and output variables. Increasing the number of hidden nodes or layers failed to improve the network performance for the training and validation data set and decreased the performance for the test data set. The output layer contained one node, that is, nitrate concentration in the catchment runoff. Resilient Propagation (Riedmiller and Braun, 1993) was used as the learning algorithm. The Stuttgart Neural Network Simulator package provided a large variety of tools to construct, train, test and prune different types of artificial neural networks (Zell et al., 1995). The time step of the neural network model was one day, corresponding to that of the INCA model. As the neural network analysis focused on the short-term $\mathrm{NO}_{3}$ dynamics, only the January 1995-April 1997 period was considered, when flow-weighted sampling was performed: stream water samples were taken by an automatic sampler whenever a certain flow volume passed the weir. Thus, every $\mathrm{mm}$ of runoff was sampled during single periods. The common cross validation approach was used. The total data set, comprising 194 tupels of variables, was split randomly into a training, validation and test data subset on a 2:1:1 ratio, irrespective of the original temporal order. The training was performed ten times, starting with different random initialisations of the weight matrix.

\section{Results}

The INCA model depicted, satisfactorily, the mean nitrate concentration in the stream as well as seasonal fluctuations (Fig. 2). However, it underestimated substantially the shortterm variance of the nitrate concentration. It (a) overestimated the annual concentration minima during the growing season and (b) did not capture the pronounced flushing during the first discharge peaks at the end of the summer season. During some events at the end of long dry periods, the measured nitrate concentrations approached $20 \mathrm{mg} \mathrm{NO}_{3} \mathrm{~L}^{-1}$ on the rising limb of the hydrograph, whereas the mean nitrate concentration measured in the stream was less than $6 \mathrm{mg} \mathrm{NO}_{3} \mathrm{~L}^{-1}$.

In addition to catchment runoff, groundwater and soil 

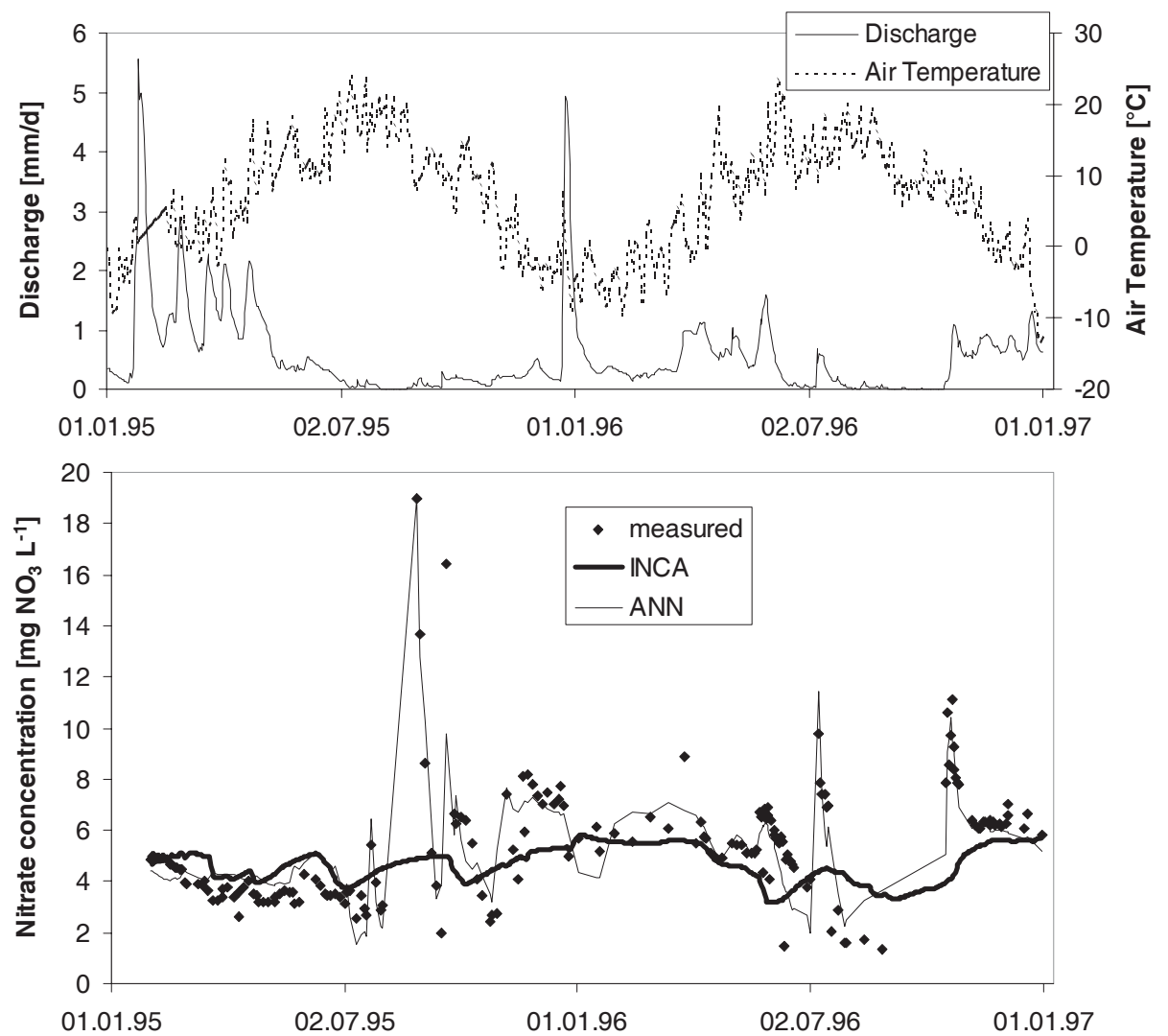

Fig. 2. Time series of annual mean discharge and temperature (upper panel) and measured and simulated $\mathrm{NO}_{3}$ concentration in the Steinkreuz runoff (lower panel).

solution data can be used to test the model. The INCA model assumes that biochemical processes do not occur below the reactive soil zone. This is consistent with the observation that the mean nitrate concentration in the deep groundwater (2000-2002) was about the same as that in the catchment runoff. Indeed, the standard deviation of the modelled stream water $\mathrm{NO}_{3}$ time series of about $1.1 \mathrm{NO}_{3} \mathrm{mg} \mathrm{L}^{-1}$ corresponds more closely to that observed in the deep groundwater (0.7 mg $\mathrm{NO}_{3} \mathrm{~L}^{-1} ; 48$ samples, November 2000-October 2002) than to that observed in the stream $\left(3.7 \mathrm{NO}_{3} \mathrm{mg} \mathrm{L}^{-1}\right)$. The observed mean nitrogen concentration of the soil solution at 60 and $90 \mathrm{~cm}$ depth does not differ significantly from that observed in the catchment runoff. Although these data exhibit substantial spatial heterogeneity, they confirm that biochemical processes are restricted to the upper $60 \mathrm{~cm}$ soil layer. However, in most cases groundwater nitrate concentrations at a depth of 2-5 m exceeded those in the stream and in the deep groundwater by a factor of up to five, especially during groundwater recharge periods. In contrast, the nitrate concentrations in the two springs $100 \mathrm{~m}$ downslope of the groundwater wells (Fig. 1) did not differ significantly from those in the stream, thereby providing evidence for a nitrogen sink between the shallow groundwater and the stream (Fig. 3).

In contrast to the INCA model, the artificial neural network explained $70 \%$ of the variance of the observed nitrate concentration. It matched the major concentration peaks accurately. This gives strong evidence that the short-term dynamics reflect rather simple relationships between the independent and the dependent variables.

The driving variables identified by the pruning procedure were daily mean air temperature and discharge on the day of sampling and the mean values of both variables for the preceding 30 days. The short-term memory of about 30 days is substantially less than the mean residence time of water in the catchment of about 1.3 years, based on ${ }^{18} \mathrm{O}$ analysis (Lischeid et al., 2004). Tracer data and soil hydrological measurements indicate that preferential flow in the unsaturated zone can be neglected (Lischeid et al., 2004). Moreover, the short-term stream water nitrogen dynamics can be reproduced without considering the throughfall nitrogen fluxes, thereby providing further evidence that preferential flow in the unsaturated zone can be neglected. It is concluded that the nitrogen dynamics observed in the 


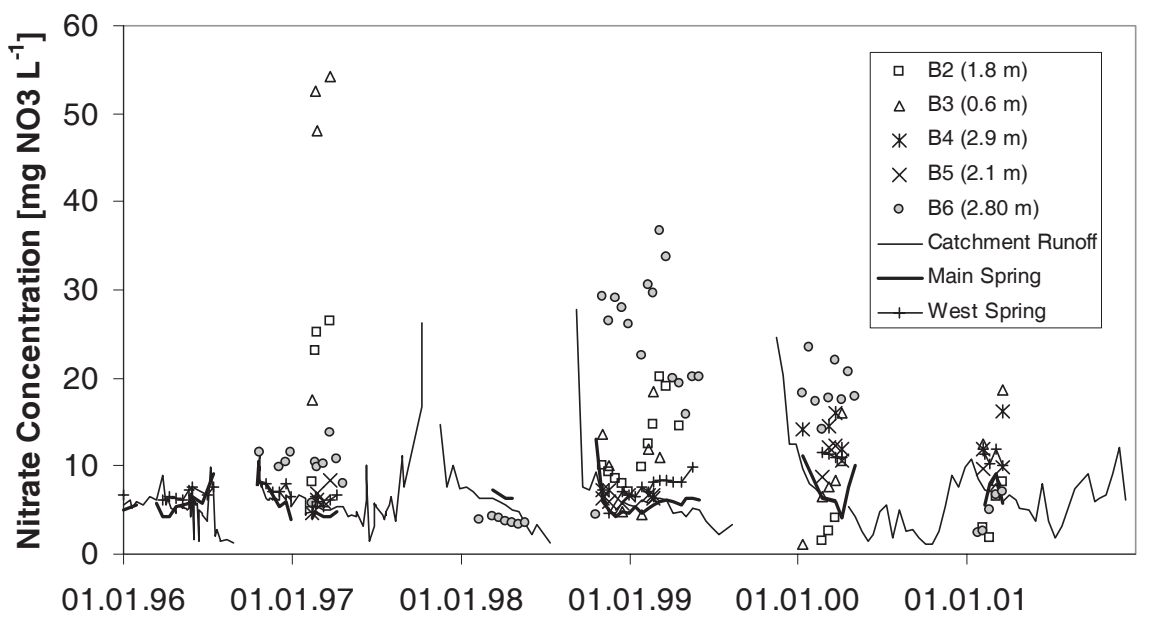

Fig. 3. $\mathrm{NO}_{3}$ concentration in the stream (three sampling sites) and in the groundwater (cf. Fig. 1 for location of the sampling sites and wells).

stream under storm-flow conditions are due mainly to processes in the riparian zone and that these riparian zone processes mask the effects of hill slope processes at highflows.

The identification of air temperature as a driving variable implies that the nitrogen dynamics were generated close to the soil surface, because the temperature signal is strongly damped in deeper soil layers. This suggests that the nitrogen dynamics are dominated by biological processes. The relationship between independent and dependent variables revealed by the neural network is consistent with the following perceptual model of nitrogen dynamics: Firstly, the mass of inorganic nitrogen compounds depends on the rate of decomposition of organic material and on the uptake rate by plants and micro organisms, where the uptake seems to lag behind decomposition. Thus, the higher the biological activity of the preceding 30 days, the higher is the amount of nitrogen easily available in the topsoil. Secondly, the percentage of these inorganic nitrogen compounds that are mobilised and transported into the stream depends on discharge: Nitrate concentration peaks in the stream are restricted to minor discharge peaks after extended warm, dry periods that leach the inorganic nitrogen into the stream. In contrast, higher discharge peaks are associated with lower nitrate concentrations, pointing to the dilution of a limited nitrate source.

\section{Discussion}

Comparing the results of the process-based INCA model with those of the data-oriented artificial neural network analysis, when combined with other monitoring studies within the catchment (Lischeid et al., 2004), helped considerably to understand the nitrogen dynamics in the Steinkreuz catchment and suggested further model improvement.

According to the artificial neural network analysis, the short-term nitrate dynamics in the stream are reproducible and fit well into a perceptual model describing the interplay between decomposition, nitrogen uptake by plants and micro organisms and short-term mobilisation of inorganic nitrogen compounds during rain storms. Similar results are reported by Mitchell (2001), Smart et al. (2001), Fölster (2000), Sánchez Pérez et al. (1999), Andersson and Lepistö (1998) and Creed et al. (1996). Moreover, artificial neural network modelling of nitrate dynamics in three different forested catchments identified the same driving variables and a similar time lag (Lischeid et al., 1998; Lischeid, 2001b; Lischeid et al., 2002).

Discharge, identified as one of the driving variables by the artificial neural network analysis, reflects a variable mixture of different contributions to runoff generation, e.g. deep groundwater, shallow groundwater and soil solution. Air temperature was also identified as a driving variable, presumably due to its correlation with biological activity in the topsoil. The length of the stream in the catchment is only about $500 \mathrm{~m}$ and stream water residence time is very short, thus, in-stream biological processes are expected to be less important in this system. Alternatively, air temperature might be an indicator of a seasonal change in the predominant flow pathways. However, there is no clear evidence for such a seasonal pattern based either on tensiometer data or on concentrations of other solutes in the stream.

Solute concentration in runoff from a catchment reflects a variety of processes inside the catchment and, thus, is often 
used to calibrate and test biogeochemical models. However, particularly under storm flow conditions, riparian zone processes might effectively mask hillslope processes irrespective of the small size of the riparian zone as a fraction of the total catchment area. Such masking has been shown for a variety of solutes, e.g. by Hooper (2001) and Smart et al. (2001), and seems to be particularly important for nitrogen (Fölster, 2000). Evidence for the prevalence of riparian zone processes in the Steinkreuz catchment is provided by the fact that the temporal variance of the nitrogen concentration in the shallow groundwater is substantially less compared to that of stream, there is no evidence for preferential flow in the unsaturated zone and the shallow groundwater nitrate concentrations are up to five times greater than those observed in the stream. Hence, there is a discrepancy between the INCA model's focus on hill slope processes and the runoff nitrogen time series used to calibrate and test the model. It is remarkable that the nitrate time series of the INCA model has approximately the same variance as the deep groundwater rather than the stream.

A more general conclusion from this study is that the nitrogen time series might be less informative with respect to catchment scale processes than often assumed when used in current process-based modelling approaches, such as INCA (Kirchner et al., 2000). Indeed, a mismatch between model structure and information content of the data used to test the model has been revealed by Lischeid and Uhlenbrook (2003). The short-term dynamics predominately determine the variance of the nitrate time series and, thus, make it difficult to calibrate a model to identify the longterm components that are more likely to reflect hill slope processes and flow-pathways. In this study, both the ANN and INCA models were calibrated to reproduce the total variance of the data set, not only that of long term components. New process-based modelling approaches that can explain both the short- and long-term in-stream dynamics must be sought.

The most striking features of the $\mathrm{NO}_{3}$ time series are the concentration peaks observed during minor discharge peaks at the end of the growing season. This so-called 'flushing' phenomenon has been observed in numerous catchments (Van Herpe and Troch, 2000; Andersson and Lepistö, 1998; Creed et al., 1996; Moldan et al., 1995). It is ascribed to rapid nitrogen leaching from the topsoil during transient saturation after dry periods when nitrogen accumulated due to mineralisation that exceeded uptake by plants and microbes (Creed et al., 1996). This interplay of mineralisation and short-term mobilisation was underestimated in setting up the INCA model and will be considered in future model exercises.

Nitrogen processes in the narrow riparian zone, which comprises less than $1 \%$ of the catchment area, are not accounted for explicitly in the INCA model. The observed flushing phenomena associated with minor water fluxes can be neglected in respect of the total output flux. However, shallow groundwater data suggest that a similar flushing behaviour, as identified by the neural network analysis, might govern groundwater recharge at upland sites as well. This has been emphasized by Creed et al. (1996).

The remarkable discrepancy between soil solution and groundwater nitrogen concentration may reflect the fact that the shallow groundwater wells sample the mobile phase, whereas the soil suction cups capture more of the immobile phase (Grossmann and Udluft, 1991; Brandi-Dohrn et al., 1996). If a significant difference exists, then soil solution data would underestimate systematically the nitrogen flux of recharging groundwater, which would have serious implications for groundwater quality risk assessments.

While flushing in the riparian zone is easily observed by stream water sampling, it is rarely identified at upland sites as the temporal resolution of soil solution and groundwater monitoring usually exceeds the typical time scale of the flushing process. The Steinkreuz data suggest that it usually occurs within a few hours, whereas the sampling interval for soil solution and groundwater is 14 days.

The shallow groundwater systematically exhibits higher nitrate concentrations than the stream, and of the two springs that discharge less than $100 \mathrm{~m}$ down slope of the wells and intercept the same groundwater layers. The groundwater level in the deep well is more than $15 \mathrm{~m}$ below the elevation of the springs and, therefore, is unlikely to contribute to reducing the nitrate concentrations in the springs. Hence, the low nitrate concentrations in the springs must be due to either a mixing of shallow groundwater with a component with a clearly lower nitrate concentration, or to an additional nitrogen sink below the rooting zone. There is no evidence for the former. However, denitrification often occurs in the clayey layers in the Keuper sandstone sediments and this may well be the most plausible explanation. An analysis of the ${ }^{18} \mathrm{O}$ and ${ }^{15} \mathrm{~N}$ compounds might help to elucidate these processes (cf. Campbell et al., 2002; Kendall 1998).

\section{Conclusions}

The artificial neural network analysis provides strong evidence that the pronounced nitrate flushing behaviour of the Steinkreuz runoff is generated in a narrow riparian zone, which was not considered explicitly in the INCA parameterisation because it was such a small fraction of the total catchment area. Correspondingly, the flushing was not reproduced by the INCA model.

This has no great effect on the total catchment budget. 
However, similar processes occur at the hill slope as well. The nitrogen load of recharging groundwater is systematically underestimated in soil solution data and, clearly, exceeds that of the catchment runoff. Hence, there must be an additional sink below the rooting zone, which is ascribed to denitrification in single clayey layers. Thus, in the INCA model, the underestimation of seepage nitrogen concentration is balanced by a corresponding underestimation of denitrification in the aquifer, below the rooting zone.

The neural network analysis of the short-term nitrate dynamics hints at processes that cannot be identified by the INCA model alone. The iterative interplay between field work, mechanistic modelling and advanced methods of data analysis improved understanding of the nitrogen dynamics in the Steinkreuz catchment. The interface between the vadose zone and groundwater deserves further investigation, particularly of the short-term dynamics. On the other hand, the results of this study emphasise the urgent need for additional measurements at the hill slope as the stream data contain little information on hill slope processes. A better understanding of these processes is a necessary prerequisite for improving long-term risk assessments, in view of, e.g. the increasing frequencies and intensities of summer rain storms predicted as a consequence of climate change.

\section{References}

Aber, J., Nadelhoffer, K.J., Steudler, P. and Melillo, J.M., 1989. Nitrogen saturation in northern forest ecosystems: hypotheses and implications. BioScience, 39, 378-386.

Andersson, L. and Lepistö, A., 1998. Links between runoff generation, climate and nitrate-N leaching from forested catchments. Water Air Soil Pollut., 105, 227-237.

Brandi-Dohrn, F.M., Dick, R.P., Hess, M. and Selker, J.S., 1996. Suction cup sampler bias in leaching characterization of an undisturbed field soil. Water Resour. Res., 32, 1173-1182.

Campbell, D.H., Kendall, C., Chang, C.C.Y., Silva, S.R. and Tonnessen, K.A., 2002. Pathways for nitrate release from an alpine watershed: Determination using $\delta^{15} \mathrm{~N}$ and $\delta^{18} \mathrm{O}$. Water Resour Res., 38, DOI: 10.1029/2001 WR000294.

Chang, S.-C., 1999. The effect of stemflow on element fluxes and soil nitrogen transformations in a mixed beech/oak stand in the Steigerwald, Germany. Bayreuther Forum Ökologie, 72, 1-107.

Creed, I.F., Band, L.E., Foster, N.W., Morrison, I.K., Nicolson, J.A., Semkin, R.S. and Jeffries, D.S., 1996. Regulation of nitrate$\mathrm{N}$ release from temperate forests: A test of the $\mathrm{N}$ flushing hypothesis. Water Resour. Res., 32, 3337-3354.

Dise, N.N. and Wright, R.F., 1995. Nitrogen leaching from European forests in relation to nitrogen deposition. Forest Ecol. Manage., 71, 153-162.

Fölster, J., 2000. The near-stream zone is a source of nitrogen in a Swedish forested catchment. J. Environ. Qual., 29, 883-893.

Grossmann, J. and Udluft, P., 1991. The extraction of soil water by the suction-cup method: a review. J. Soil Sci., 42, 83-93.

Hooper, R.P., 2001. Applying the scientific method to small catchment studies: A review of the Panola Mountain experience. Hydrol. Process., 15, 2039-2050.
Hornberger, G.M., Bencala, K.E. and McKnight, D.M., 1994. Hydrological controls on dissolved organic carbon during snowmelt in the Snake River near Montezuma, Colorado. Biogeochemistry, 25, 147-165.

Huang, W.R. and Foo, S., 2002. Neural network modeling of salinity variation in Apalachicola River. Water Res., 36, 356362.

Kendall, C., 1998. Tracing nitrogen sources and cycles in catchments. In: Isotope Tracers in Catchment Hydrology, C. Kendall and J.J. McDonnell (Eds.), Elsevier, Amsterdam, The Netherlands. 519-576.

Kirchner, J.M., Feng, X. and Neal, C., 2000. Fractal stream chemistry and its implications for contaminant transport in catchments. Nature, 403, 524-527.

Langusch, J.-J. and Kalbitz, K., 2001. Bodenkundliche Charakterisierung der Intensiv-Messfläche Steinkreuz. In: Waldökosystemforschung in Nordbayern: Die BITÖKUntersuchungsflächen im Fichtelgebirge und Steigerwald, P.Gerstberger(Ed.), Bayreuther Forum Ökologie no. 90, BITÖK, University of Bayreuth, Germany. 159-167.

Langusch, J.-J. and Matzner, E., 2002. N fluxes in two nitrogen saturated forested catchments in Germany: dynamics and modelling with INCA. Hydrol. Earth Syst. Sci., 6, 383-394.

Lischeid, G., 2001a. Investigating short-term dynamics and longterm trends of $\mathrm{SO}_{4}$ in the runoff of a forested catchment using artificial neural networks. J. Hydrol., 243, 31-42.

Lischeid, G., 2001b. Investigating trends of hydrochemical time series of small catchments by artificial neural networks. Phys. Chem. Earth Part B, 26, 15-18.

Lischeid, G. and Uhlenbrook, S., 2003. Checking a process-based catchment model by artificial neural networks. Hydrol. Process., 17, 265-277.

Lischeid, G., Lange, H. and Hauhs, M., 1998. Neural network modelling of $\mathrm{NO}_{3}^{-}$- time series from small headwater catchments. IAHS Publication no. 248, 467-473.

Lischeid, G., Büttcher, H., Krám, P. and Hruška, J., 2002. Comparative analysis of hydrochemical time series of adjacent catchments by process-based and data-oriented modeling. Proc. Third Int. Conf. Water Resources and Environment Research (ICWRER), Dresden, July 22-25.

Lischeid, G., Lange, H., Moritz, K. and Büttcher, H., 2004. Dynamics of runoff and runoff chemistry at the Lehstenbach and Steinkreuz catchment. In: Biogeochemistry of forested catchments in a changing environment: a case study in NEBavaria, E.Matzner, (Ed.). Ecological Studies 172, Springer, Germany. 399-436.

Lovett, G.M., Weathers, K.C. and Sobaczak, W.V., 2000. Nitrogen saturation and retention in forested watersheds of the Catskill Mountains, New York. Ecol. Appl., 10, 73-84.

Maier, H.R. and Dandy, G.C., 1996. The use of artificial neural networks for the prediction of water quality parameters. Water Resour. Res., 32, 1013-1022.

Mitchell, M., 2001. Linkage of nitrate losses in watersheds to hydrological processes. Hydrol. Process., 15, 3305-3307.

Moldan, F., Hultberg, H., Nyström, U. and Wright, R.F., 1995. Nitrogen saturation at Gårdsjön, southwest Sweden, induced by experimental addition of ammonium nitrate. Forest Ecol. Manage., 71, 89-97.

Mozer, M.C. and Smolensky, P., 1989. Skeletonization: a technique for trimming the fat from a network via relevance assessment. Advan. Neural Network Inform. Process. Syst., 1, 107-115.

Riedmiller, M. and Braun, H., 1993. A direct adaptive method for faster Backpropagation learning: The Rprop algorithm. Proc. IEEE Int. Conf. Neural Networks (ICNN), San Francisco, USA. 586-591. 
Sánchez Pérez, J.M., Tremolieres, M., Takatert, N., Ackerer, P., Eichhorn, A. and Maire, G., 1999. Quantification of nitrate removal by a flooded alluvial zone in the Ill floodplain (Eastern France). Hydrobiologia, 410, 185-193.

Simúnek, J., Sejna, M. and van Genuchten, T., 1996. HYDRUS2D simulating water flow and solute transport in twodimensional variably saturated media. Int. Ground Water Model. Center, Golden Colorado, USA. 167pp.

Smart, R.P., Soulsby, C., Cresser, M.S., Wade, A.J., Townend, J., Billett M.F. and Langan, S., 2001. Riparian zone influence on stream water chemistry at different spatial scales: a GIS-based modelling approach, an example for the Dee, NE Scotland. Sci. Total Envir., 280, 173-193.

Stoddard, J.L., Jeffries, D.S., Lükewille, A., Clair, T.A., Dillon, P.J., Driscoll, C.D., Forsius, M., Johannessen, M., Kahl, J.S., Kellogg, J.H., Kemp, A., Mannio, J., Monteith, D.T., Murdoch, P.S., Patrick, S., Rebsdorf, A., Skjelkvale, B.L., Stainton, M.P., Traaen, T., van Dam, H., Webster, K.E., Wieting, J. and Wilander, A., 1999. Regional trends in aquatic recovery from acidification in North America and Europe. Nature, 401, 575578.

Stoddard, J.L., Traaen, T.S. and Skjelkvåle, B.L., 2001. Assessment of nitrogen leaching at ICP-Waters sites (Europe and North America). Water Air Soil Pollut., 130, 781-786.

Van Herpe, Y. and Troch, P.A., 2000. Spatial and temporal variations in surface water nitrate concentrations in a mixed land use catchment under humid temperate climatic conditions. Hydrol. Process., 14, 2439-2455.

Wade, A.J., Durand, P., Beaujouan, V., Wessel, W.W., Raat, K.J., Whitehead, P.G., Butterfield, D., Rankinen, K. and Lepistö, A., 2002. A nitrogen model for European catchments: INCA, new model structure and equations. Hydrol. Earth. Syst. Sci., 6, 559582. (See also Errata. Hydrol. Earth. Syst. Sci., 8, 858-859.)
Walter, M., Recknagel, F., Carpenter, C. and Bormans, M., 2001. Predicting eutrophication effects in the Burrinjuck Reservoir (Australia) by means of the deterministic model SALMO and the recurrent neural network model ANNA. Ecol. Model., 146, 97-113.

Welsch, D.L., Kroll, C.N., McDonnell, J.J. and Burns, D.A., 2001. Topographic controls on the chemistry of subsurface stormflow. Hydrol. Process., 15, 1925-1938.

Whitehead, P.G., Wilson, E.J. and Butterfield, D., 1998a. A semidistributed integrated nitrogen model for multiple source assessment in catchments (INCA): Part I - model structure and process equations. Sci. Total Envir., 210/211, 547-558.

Whitehead, P.G., Wilson, E.J., Butterfield, D. and Seed, K., 1998b. A semi-distributed integrated nitrogen model for multiple source assessment in catchments (INCA): Part I - application to large river basins in South Wales and Eastern England. Sci. Total Envir, 210/211, 559-583.

Wright, R.W. and Hauhs, M., 1991. Reversibility of acidification: soils and surface waters. Proc. Roy. Soc. Edinburgh, 97B, 1691991

Zell, A., Mamier, G., Vogt, M., Mache, N., Hübner, R., Döring, S., Herrmann, K-U., Soyez, T., Schmalzl, M., Sommer, T., Hatzigeorgiou, A., Posselt, D., Schreiner, T., Kett, B., Clemente, G., Wieland, J., Reczko, M., Riedmiller, M., Seemann, M., Ritt, M., DeCoster, J., Biedermann, J., Danz, J., Wehrfritz, C., Werner, R., Berthold, M. and Orsier, B., 1995. Stuttgart Neural Network Simulator user manual, Version 4.1. University of Stuttgart, Institute for Parallel and Distributed High Performance Systems, Report No. 6/95.279pp. 